\title{
Reduction of cardiovascular risk in patients with metabolic syndrome in a community health center after a pharmaceutical care program of pharmacotherapy follow-up
}

\author{
Camila Pedro Plaster ${ }^{1}$, Danilo Travassos Melo ${ }^{1}$, Veraci Boldt ${ }^{1}$, Karla Oliveira dos Santos Cassaro ${ }^{1}$, \\ Fernanda Campos Rosetti Lessa ${ }^{1}$, Giovanna Assis Pererira Boëchat ${ }^{1}$, Nazaré Souza Bissoli ${ }^{2}$, Tadeu \\ Uggere de Andrade ${ }^{1,3, *}$
}

\author{
${ }^{1}$ Department of Pharmacy, University of Vila Velha, ${ }^{2}$ Department of Physiological Sciences, Federal University of Espirito \\ Santo, ${ }^{3}$ Department of Pharmaceutical Sciences, Federal University of Espirito Santo
}

\begin{abstract}
The objective of this study was to determine the impact of a pharmaceutical care (PC) program in a sample of public outpatients with metabolic syndrome (MS) who were being treated in Brazil's health system; the patients were randomized into PC or standard care. The pharmacotherapy follow-up (PF) was performed in a total of 120 patients with type 2 diabetes for 6 months. Adherence to treatment (measured with the Morisky test), negative outcomes associated with medication (NOM) and anthropometric and biochemical parameters were measured before and after PF. The Framingham scoring method was used to estimate changes in 10-year coronary heart disease risk scores in all patients. Ninety-six of 120 patients had characteristics of MS and were randomized into two groups $(\mathrm{G})$ : the control group (CG: 36) and the intervention group (IG: 38). Among the MS patients, 100\% were taking a glucose-lowering drug; many were also taking anti-hypertensive drugs (CG: 72\%; IG: 73\%), and some patients were also taking hypolipemic drugs (CG: $12.0 \%$; IG: $14.7 \%$ ). Only $20.7 \%$ of the IG patients were considered adherent to their prescribed drugs. In the CG, an increase of coronary heart disease (CHD) risk ( $22 \pm 2$ to $26 \pm 3$; $\mathrm{p}<0.05)$ was observed, while in the $\mathrm{IG}$, there was a reduction in CHD risk $(22 \pm 2$ to $14 \pm 2 \% ; \mathrm{p}<0.01)$. The PC program administered to patients with MS monitored through the primary healthcare services of the Brazilian public health system improved patient health, resulting in clinical improvements and a decrease in cardiovascular risk in IG patients over a period of ten years.
\end{abstract}

Uniterms: Pharmaceutical service. Metabolic syndrome/cardiovascular risk. Drug therapy follow-up. Medicines/associated negative outcomes.

\begin{abstract}
O objetivo deste estudo foi o de determinar o impacto de um Programa de atenção Farmacêutica (AF) em uma amostra de pacientes ambulatoriais de Sistema Público de Saúde do Brasil portadores de Síndrome Metabólica, randomizados em $\mathrm{AF}$ ou atenção à saúde usual. Realizou-se o seguimento farmacoterapêutico com 120 pacientes com diabetes tipo 2 durante seis meses. Avaliou-se o nível de aderência ao tratamento (teste Morisky), resultados clínicos negativos associados a medicamentos (RNM), parâmetros bioquímicos e antropométricos, antes e após o seguimento. O método de Framingham foi usado para calcular as variações no risco de doenças coronarianas em 10 anos em todos os pacientes. Dos 120 pacientes, 96 tiveram características de SM e foram então randomizados em dois grupos (G): Controle (GC: 36$)$ e Intervenção (GI: 38). Entre os pacientes com SM, 100\% faziam uso de medicamentos para diminuir a glicose, anti-hipertensivos (GC: 72\%; GI: 73\%) e hipoglicemiantes (GC: 12.0\%; GI: 14.7\%). Apenas $20,7 \%$ do GI foram considerados aderentes aos fármacos prescritos. No GC foi observado aumento do risco de Doença Arterial Coronariana (DAC) $(22 \pm 2$ para $26 \pm 3 ; p<0,05)$, enquanto no GI foi observado redução (22 \pm 2 para $14 \pm 2 \%$; $<<0,01)$. O Programa de AF para pacientes com SM monitorados na atenção primária do Sistema de Saúde Pública brasileiro melhora o funcionamento do serviço resultando na melhoria clínica dos pacientes com redução do risco de doença cardiovascular em um período de dez anos.
\end{abstract}

Unitermos: Atenção farmacêutica. Síndrome metabólica/risco cardiovascular. Seguimento farmacêutico. Medicamentos/resultados negativos associados.

\footnotetext{
*Correspondence: Tadeu Uggere de Andrade. Rua Comissário José Dantas de Melo, 21 - 29102-770 - Boa Vista - Vila Velha - ES, Brazil. Tel: 55-27-3421-2198; Fax: 55-27-3421-2049. E-mail: tadeu.andrade@uvv.br
} 


\section{INTRODUCTION}

Metabolic syndrome (MS) is a set of interconnected risk factors of metabolic origin that may contribute to the development of atherosclerotic cardiovascular disease (ACD) (Grundy et al., 2005). Additionally, patients affected by MS are 5 times more likely to develop diabetes (Lakka et al., 2002).

Metabolic syndrome is characterized by the presence of dyslipidemia, glucose intolerance, hypertension and excess weight or abdominal obesity, among other abnormalities, as defined by the National Cholesterol Education Program's Adult Treatment Panel III (NCEP ATP-III) (NCEP, 2002). Consequently, MS triggers a number of chronic diseases that require changes in patients' lifestyles, such as weight reduction, increased physical activity and non-atherogenic diets, to slow down the progress of the disease. However, solely making lifestyle changes may be insufficient to reverse all risk factors. In such cases, the establishment of a drug regimen is recommended to minimize each patient's clinical events. Because there is currently no single drug that can reverse the known progression of MS in the long term, it is necessary to treat each one of the risk factors separately, thus necessitating polypharmacy (Grundy et al., 2005).

Such interventions can often be ineffective because of patient noncompliance with treatment, problems related to health services, socio-economic issues, adverse reactions to treatment and the stage of the disease and associated complications or the presence of co-morbidities (Lessa, 1998).

Adherence is defined as the degree of correlation between a patient's behavior in relation to medical guidelines or the advice of health professionals (Lessa, 1998). Adherence to treatment is, therefore, a fundamental condition for the control of non-transmissible chronic diseases (Hill, Miller, Degeest, 2011) such as MS.

Consequently, patients with MS may be at risk for developing negative outcomes associated with medication (NOM), justifying the practice of pharmaceutical care (PC), which aims to optimize pharmacological treatment and improve the patient's quality of life (Robinson et al., 2010).

$\mathrm{PC}$ practice is expanding worldwide. A systematic review examining the effectiveness of $\mathrm{PC}$ to improve patient outcomes from 1990 to 2003 showed evidence that PC services improve medication use and surrogate end points such as blood pressure, cholesterol levels and glycosylated hemoglobin (Rougheade, Semples, Vitrya, 2005). There have been several reports on experiences with PC programs that addressed patients with hypertension (Castro et al., 2006; Bhatt, Luqman-Arafath, Guleria, 2007), diabetes (Horswell et al., 2008; Adepu, Rasheed,
Nagavi, 2007) and/or dyslipidemia (Tsuyuki et al., 2002; Chisholm, Spivey, Mulloy, 2007). A meta-analysis by Ni, Chen and Huang (2009) evaluated the association between PC and the control of hypertension, demonstrating that PC programs could significantly improve blood pressure control in patients with hypertension. However, a systematic review by Aguiar et al. (2012) showed a lack of hardiness and many important limitations in the studies concerning the use of PC in hypertension. The authors recommended improvements in research design and in the demonstration of the intervention's effectiveness. Adepu et al. (2007) showed that $\mathrm{PC}$ had a positive impact on diabetes treatment by promoting increased patient awareness of the disease and changes in dieting and lifestyle, improving glycemic control and the patients' quality of life. Tsuyuki et al. (2002), in the Study of Cardiovascular Risk Intervention by Pharmacists (SCRIP), demonstrated that high-risk patients who received pharmaceutical intervention showed improvement in their cholesterol management.

Experiences with $\mathrm{PC}$ have also been reported in Brazil. Castro et al. (2006) observed that a group of patients with uncontrolled hypertension accompanied by a program of PC showed a trend of greater clinical improvement than did the group treated by other professionals but not by a pharmacist. Neto et al. (2011) found that a PC program in a community health care unit resulted in better clinical measurements and reduced cardiovascular risk scores in elderly diabetic and hypertensive patients over a 36-month period. Correr et al. (2011) demonstrated that a pharmacotherapy follow-up of type 2 diabetic patients in community pharmacies improved patients' glycemic control. Our group showed that PC improves patient pharmacy service satisfaction levels as compared with the satisfaction with pharmacies, both private and public, without a PC program (Andrade et al., 2009).

However, we did not find any studies that addressed the results of a PC program in patients with MS in community health centers $(\mathrm{CHC})$ in a public health system. Therefore, this study aimed to determine the impact of a PC program in a sample of public outpatients with MS being treated in Brazil's health system; patients were randomized into PC or standard care. We hypothesized that $\mathrm{PC}$ would improve the clinical parameters of the patients, with a consequent reduction of cardiovascular risk.

\section{METHODOLOGY}

\section{Study design of pharmaceutical care program evaluation}

The primary healthcare of the Brazilian public health 
system takes place in $\mathrm{CHCs}$, where patients receive free health care from professionals in medicine, dentistry, nursing, community health and others; pharmacists are present in many but not all of these CHCs. Their work is not related to healthcare, but simply to purchasing and dispensing medicines. The primary healthcare services are organized into health programs such as "HiperDia," which is focused on the control and prevention of hypertension and diabetes.

This study was a randomized, controlled, longitudinal, prospective clinical trial carried out from October 2008 to April 2009 in outpatients from a CHC in Vila Velha (ES, Brazil). In this CHC, 120 patients were casually selected from a population of 174 patients with diabetes (type 2) attended by one team of the "HiperDia" program $(\mathrm{CI}=95 \% ; \alpha=0.05)$.

In this sample, the presence of MS was evaluated according to the criteria of the National Cholesterol Education Program (NCEP-ATPIII) (NCEP, 2002) and the Brazilian Guidelines for the Diagnostic and Treatment of MS (BGMS) (Sociedade Brasileira de Hipertensão, 2004): abdominal obesity ( $>102 \mathrm{~cm}$ for men and $>88$ $\mathrm{cm}$ for women); hypertriglyceridemia ( $>150 \mathrm{mg}^{\mathrm{d} \mathrm{dL}^{-1}}$ ); reduced HDL-cholesterol $\left(<40 \mathrm{mg} \cdot \mathrm{dL}^{-1}\right.$ in men and $<50$ mg.dL ${ }^{-1}$ in women); hypertension $(>130 / 85 \mathrm{mmHg}$ ) and fasting glucose $\left(>110 \mathrm{mg} \cdot \mathrm{dL}^{-1}\right)$. Patients identified with MS ( $n=96)$ were invited to participate in this study, and we performed a case-controlled and randomized study with 74 of those patients who agreed to participate. The inclusion criterion was that patients had to meet at least three of the conditions recommended by the NCEP-ATP III and BGMS for the diagnosis of MS.

These patients were randomized into two groups: control $(\mathrm{n}=36)$ and intervention $(\mathrm{n}=38)$. The random allocation was performed in blocks of six patients each and stratified by gender through a computer-generated sequence. The control group was typically accompanied by members of the $\mathrm{CHC}$ team (including physician, nurse, nursing assistant, community agents, and others, but not a pharmacist) and only initially interviewed by the pharmaceutical care team to determine socio-economic and cultural data, update the pharmacotherapeutic history and determine any negative outcomes associated with medication $(\mathrm{NOM})$.

The intervention group, in addition to receiving the initial interview and monitoring by the $\mathrm{CHC}$ team, participated in the PC program, according to the Dáder methodology (Machuca, Fernández-Llimós, Faus, 2003). In both groups, NOMs were identified and ranked (Comité de Consenso, 2007) when the requirements for the rational indication, effectiveness or safety were not satisfactory. In the intervention group, pharmaceutical interventions were proposed to resolve or prevent the NOMs.

After six months of follow-up, patients from both groups had their anthropometric data, laboratory parameters and blood pressure measured again. The results of the two groups were then analyzed and compared. The initial and final measures were taken by pharmacists blind to the study.

This study was previously approved by the Institutional Ethics Committee for Research on Humans Beings of the University of Vila Velha (protocol number 09/2006).

\section{Evaluation of the mean arterial pressure (MAP), anthropometric and laboratory parameters}

In this first interview, the presence of MS was determined by the measurement of blood pressure (BP) using an automatic blood pressure unit (HEM-705CPINT, Omron, Omron Healthcare, Inc., Illinois, USA). The individuals' pressure levels were rated according to the criteria of the VII Joint National Committee (National High Blood Pressure Education Program, 2004). A clamp suitable for obese patients was used when needed. Anthropometric measurements were taken, such as height and weight using mechanical isometric balance (Welmy, Sao Paulo - Brazil) and abdominal circumference (AC), using an inelastic tape positioned in the middle of the distance between the iliac crest and the lower costal margin (Sociedade Brasileira de Hipertensão, 2007). Biochemical parameters, such as fasting glucose, triacylglycerols, HDL-C, low density lipoprotein-cholesterol (LDL-C) and total cholesterol, were also measured using the enzymatic method (kit of reagents: Bioclin, Goiás, Brazil; Spectrophotometer: BIOPLUS Bio-200, Bio 200F, SP, Brazil).

The same procedure was carried out after a period of six months in both groups, according to the same protocol. The collection of these data and laboratory analyses was performed by pharmacists who did not participate in the monitoring of the patients and were therefore not aware to which group the patients belonged.

\section{Socio-economic-cultural and pharmacotherapeutic history data collection}

A structured questionnaire, divided into three sections, was applied in the first meeting with patients from both groups. In the first section, socio-economic information was collected, including age, gender and family income. In the second section, patients' knowledge of MS and their family histories of diabetes and cardiovascular disease were addressed; information was also collected on 
eating habits, practice of physical activity, consumption of alcohol, smoking and the presence of prior cardiovascular co-morbidities. In the third section, patients' pharmacotherapeutic data were collected, with a focus on medicines used for the control of clinical events related to the MS.

\section{Monitoring of patients in the control group}

After the first interview, patients in the control group had no more pharmaceutical interventions except to confirm with the $\mathrm{CHC}$ team that the patients were adhering to the "Hiperdia" program, including attending all the consultations and/or participating in all the interventions recommended by the program during the study period. The exclusion criterion for patients in the control group was lack of adherence to this healthcare program. According to this criterion, seven patients were excluded, and their initial data are not part of the results of this work.

\section{Monitoring of patients in the intervention group - pharmaceutical care program}

The patients in the intervention group, in addition to participating in the initial interview, were accompanied by the PC program in accordance with the Dáder methodology (Machuca, Fernández-Llimós, Faus, 2003), which was adapted to the reality of outpatient $\mathrm{CHC}$ care. The care protocols and monitoring instruments used were based on protocols and tools that had been previously validated (Baena et al., 2001). Information, such as primary health complaint, symptoms and the presence of allergic reactions, was collected. Data on medicine, dosage, route of administration and frequency of use were also evaluated.

The Third Consensus of Granada (Comité de Consenso, 2007) proposed and adopted the following definition of "negative outcomes associated with medication": "patient health outcomes that are not consistent with the objectives of pharmacotherapy and are associated with the use or errors in the use of medicines." A NOM was diagnosed when rational indication, effectiveness, or safety requirements were not satisfied. The most likely reasons and possible solutions for the occurrence of NOM were discussed with the patient by the pharmacist. In more complex situations, the pharmacist discussed the problem with the consulting physician; this strategy is part of the Dáder method, and because some problems could have serious consequences, it was applied to the control group as well (Castro et al., 2006).

Performing an analysis related to medicine usage, NOMs were identified according to the Third Consensus of Granada (Comité de Consenso, 2007). The NOMs were classified into three groups: necessity, effectiveness and safety.

The follow-up program in the intervention group occurred over six months, with a monthly pharmaceutical interview and more frequent contact by phone when necessary. The pattern of therapeutic goals to be reached, medicine indication and dosage regimen of the NECPATP III (NCEP, 2002) and BGMS (Sociedade Brasileira de Hipertensão, 2004) were used to evaluate whether the patients' clinical conditions were under control and whether the proper pharmacotherapeutic standards were being used. In this way, the necessity, effectiveness and safety of the pharmacological treatment were identified and the NOMs were determined.

Treatment evaluation was performed in each inperson meeting by BP and anthropometric measurement (as described earlier in this study) and by the capillary determination of the fasting glucose, triglycerides and cholesterol (Accutrend GCT monitor, Roche, São Paulo, SP, Brazil; reagent tests tips: Accutrend Glucose, Triglycerides, Cholesterol, Roche, São Paulo, SP, Brazil). Meetings were scheduled at least $24 \mathrm{~h}$ in advance. Patients who did not attend six PC interviews and all meetings of the "Hiperdia" program were considered non-adherent to the PC program and were excluded from the study. Four subjects attended fewer than six meetings, and their data were not used in this work.

The pharmaceutical interventions were grouped into three broad categories: a) lifestyle; b) correct use of the medicines and c) pharmacist-doctor interaction. Interventions were oral, written or both, and educative instructional material about lifestyle modifications was distributed. The interventions with the physicians were conducted orally, by letter, or both.

The primary reasons and possible solutions for the NOMs identified were discussed with the patients by the PC team; in more complex cases where the doctor's intervention was required, the clinical team was notified.

NOMs were only considered resolved when the negative clinical results found reverted to standard values (Pan-American Health Organization, 2007). A potential NOM was considered prevented when it did not manifest during the follow-up period and when a pharmaceutical intervention was performed to prevent it.

\section{Evaluation of adherence levels to the pharmacological treatment - The Morisky test}

The Morisky test (Morisky, Green, Levine, 1986) was applied to help evaluate patient adherence levels to pharmacological treatment. According to this test, patients 
are considered adherent (high adherence level) when their answers to all four test questions are negative. When any one of the questions is answered positively, the patient is considered non-adherent (low adherence level). It is also possible to characterize whether the low level of adherence is intentional or non-intentional (Table I).

\section{Cardiovascular risk evaluation}

To evaluate cardiovascular risk, the revised Framingham criteria (Wilson et al., 1998) were applied to both control and intervention groups at the beginning and the end of the study period. According to the Framingham score, a patient's risk for developing cardiovascular disease (CVD) in ten years is calculated by the sum of the points assigned for the following variables: age, gender, plasmatic LDL-cholesterol, HDL-cholesterol, blood pressure, presence of diabetes and smoking (Wilson et al., 1998).

\section{Statistical analysis}

Statistical analysis was carried out using SPSS for Windows, version 13.0 (SPSS Inc., Chicago, USA). Simple relative frequencies were performed with the qualitative variables in each group and were also compared between the two groups (cross frequencies). The Chi-square test was applied to the significance level of $5 \%$. Descriptive statistics were applied to the quantitative variables, and the differences were determined using parallel (within the same group) and non-parallel (between the groups) Student $t$ tests for a confidence interval of $95 \%$. These data were expressed as the mean \pm standard error of the mean (SEM).

\section{RESULTS}

\section{Initial profile of the patients in the Control and Intervention groups}

A high frequency of MS (80\%) was identified in diabetic outpatients from the CHC in Vila Velha (ES, Brazil).
This result was unsurprising because diabetes was present in all patients and only two additional criteria from NECPATP-III (NCEP, 2002) or BGMS (Sociedade Brasileira de Hipertensão, 2004) were necessary for a diagnosis of MS. As such, 96 of 120 patients were identified with MS.

Table II shows data related to the age, gender, family income, lifestyle and cardiovascular disease family history of the patients in the control and intervention groups. In both groups, the subjects were primarily underprivileged (receiving approximately $1-2$ times the Brazilian minimum salary, i.e., US\$250.00 monthly), female and elderly. There were no significant differences among the variables between the two groups $(\mathrm{P}>0.05)$.

The initial values of systolic (SAP) and diastolic arterial pressure (DAP), anthropometric measures and biochemistry parameters of both groups are shown in Table III. Statistical analysis indicated that the groups were well matched ( $\mathrm{P}>0.05$ in all cases).

In terms of the number of medications in use by both groups, all patients were taking at least one medicine. Antidiabetic drugs were the primary type of medication in use $(100 \%$ of patients in both groups were taking anti-diabetic drugs), followed by anti-hypertensive drugs $(72.0 \% ; n=21$ in the Control group and $73.5 \% ; n=25$ in the Intervention group). Hypolipemic drugs were less frequently used $(12.0 \% ; n=4$ in the Control group and $14.7 \% ; n=5$ in the Intervention group). The most frequent number of medications in use was three to four ( $52 \%$ and $50 \%$ for control and intervention groups, respectively), followed by one to two medicines ( $28 \%$ and $29.4 \%$ for control and intervention groups, respectively) and then five or more ( $21 \%$ and $22 \%$ for control and intervention groups, respectively). The frequencies were not statically different between the groups studied $(\mathrm{P}>0.05)$.

One hundred thirty-two and 129 NOMs were identified in the Control and Intervention groups, respectively $(\mathrm{P}>0.05)$. The primary NOMs were those related to efficiency $($ Control $=48.5 \%, n=64$; Intervention $=47.3 \%$, $\mathrm{n}=61 ; \mathrm{P}>0.05)$, followed by safety (Control $=35.2 \%$, $\mathrm{n}=45$; Intervention $=36.4 \%, \mathrm{n}=47 ; \mathrm{P}>0.05)$ and necessity $($ Control $=17.4 \%, n=23$; Intervention $=16.3 \%, n=21$; $\mathrm{P}>0.05)$.

TABLE I - Questions on the Morisky test and the adherence level classification indicated by positive answers to the questions

\begin{tabular}{lcc}
\hline Morisky test Questions & Non-intentional & Intentional \\
\hline "Do you sometimes forget to take your medicine?" & $\mathrm{X}$ & $\mathrm{X}$ \\
"Are you sometimes careless about taking your medicine at the scheduled time?" & & $\mathrm{X}$ \\
"When you feel good, do you sometimes stop taking your medicine?" & $\mathrm{X}$ \\
\hline "When the medicine makes you feel bad, do you sometimes stop taking it?" & \\
\hline
\end{tabular}


TABLE II - Socio-economic, lifestyle and cardiovascular disease family history of patients from the Control and Intervention groups

\begin{tabular}{|c|c|c|c|c|}
\hline & \multicolumn{2}{|c|}{ Intervention } & \multicolumn{2}{|c|}{ Control } \\
\hline & $\%$ & $\mathrm{n}$ & $\%$ & $\mathrm{n}$ \\
\hline \multicolumn{5}{|l|}{ AGE (YEARS) } \\
\hline $30-39$ & 2.9 & 1 & 0 & 0 \\
\hline $40-59$ & 44.1 & 15 & 36.0 & 10 \\
\hline 60 or older & 52.9 & 18 & 64.0 & 19 \\
\hline \multicolumn{5}{|l|}{ GENDER } \\
\hline Male & 29.4 & 10 & 40.0 & 12 \\
\hline Female & 70.6 & 24 & 60.0 & 17 \\
\hline \multicolumn{5}{|c|}{ FAMILY INCOME (Brazilian minimum wage*) } \\
\hline $1-2$ & 64.7 & 22 & 72.0 & 21 \\
\hline $3-4$ & 29.4 & 10 & 24.0 & 7 \\
\hline$\geq 5$ & 5.9 & 2 & 4.0 & 1 \\
\hline \multicolumn{5}{|c|}{ DO YOU PRACTICE PHYSICAL ACTIVITY? } \\
\hline Yes & 38.2 & 13 & 40.0 & 12 \\
\hline No & 61.8 & 21 & 60.0 & 17 \\
\hline \multicolumn{5}{|c|}{ ARE YOU ON A DIET? } \\
\hline Yes & 82.4 & 28 & 84.0 & 24 \\
\hline No & 17.6 & 6 & 16.0 & 5 \\
\hline \multicolumn{5}{|c|}{ IS THERE ANY HISTORY OF CARDIOVASCULAR DISEASE IN YOUR FAMILY? } \\
\hline Yes & 70.6 & 24 & 72.0 & 21 \\
\hline No & 29.4 & 10 & 28.0 & 8 \\
\hline
\end{tabular}

* Brazilian minimum wage in 2012 corresponds to US\$245.00

TABLE III - Values of SAP and DAP and anthropometric and biochemistry data of the Control and Intervention groups

\begin{tabular}{|c|c|c|c|c|}
\hline & \multicolumn{2}{|c|}{ Initial } & \multicolumn{2}{|c|}{ Final } \\
\hline & $\begin{array}{l}\text { Control } \\
(\mathrm{n}=36)\end{array}$ & $\begin{array}{l}\text { Intervention } \\
\quad(\mathrm{n}=38)\end{array}$ & $\begin{array}{l}\text { Control } \\
(\mathrm{n}=29)\end{array}$ & $\begin{array}{c}\text { Intervention } \\
\quad(\mathrm{n}=34)\end{array}$ \\
\hline $\mathrm{SAP}(\mathrm{mm} \mathrm{Hg})$ & $138 \pm 3$ & $138 \pm 4$ & $141 \pm 4$ & $131 \pm 3^{\text {ae }}$ \\
\hline $\mathrm{DAP}(\mathrm{mm} \mathrm{Hg})$ & $80 \pm 1$ & $80 \pm 2$ & $81 \pm 3$ & $78 \pm 2$ \\
\hline SAPH (mm Hg) & $146 \pm 2$ & $149 \pm 4$ & $147 \pm 5$ & $133 \pm 4^{\text {ace }}$ \\
\hline DAPH (mm Hg) & $81 \pm 2$ & $85 \pm 3$ & $81 \pm 3$ & $78 \pm 2^{\text {bdf }}$ \\
\hline Body weight (Kg) & $80 \pm 4$ & $79 \pm 3$ & $81 \pm 4$ & $78 \pm 4$ \\
\hline Men WC (cm) & $102 \pm 3$ & $106 \pm 4$ & $103 \pm 4$ & $105 \pm 4$ \\
\hline Women WC (cm) & $104 \pm 3$ & $102 \pm 2$ & $105 \pm 4$ & $94 \pm 2^{\text {ace }}$ \\
\hline Plasma glucose $\left(\mathrm{mg} \cdot \mathrm{dL}^{-1}\right)$ & $181 \pm 14$ & $198 \pm 15$ & $173 \pm 13$ & $130 \pm 12^{\mathrm{bdf}}$ \\
\hline Total cholesterol (mg.dL dL $\left.^{-1}\right)$ & $209 \pm 7$ & $205 \pm 9$ & $210 \pm 4$ & $182 \pm 5^{\text {bdf }}$ \\
\hline Triglycerides $\left(\mathrm{mg} \cdot \mathrm{dL}^{-1}\right)$ & $207 \pm 20$ & $186 \pm 15$ & $174 \pm 14$ & $165 \pm 13$ \\
\hline Men HDL-c (mg.dL-1) & $44 \pm 3$ & $40 \pm 3$ & $40 \pm 3$ & $47 \pm 2^{\text {ace }}$ \\
\hline Women HDL-c (mg.dL $\left.{ }^{-1}\right)$ & $45 \pm 3$ & $42 \pm 2$ & $41 \pm 3$ & $49 \pm 1^{\text {ce }}$ \\
\hline $\mathrm{LDL}\left(\mathrm{mg} \cdot \mathrm{dL}^{-1}\right)$ & $140 \pm 6$ & $146 \pm 6$ & $132 \pm 4$ & $111 \pm 5^{\mathrm{bdf}}$ \\
\hline
\end{tabular}

SAP: systolic arterial pressure; DAP: diastolic arterial pressure; SAPH: SAP of hypertensive patients; DAPH: DAP of hypertensive patients; WC: waist circumference. Values are expressed as the mean \pm SEM. ${ }^{a} p<0.05$ and ${ }^{b} p<0.01$ compared with initial control group data; ${ }^{c} p<0.05$ and ${ }^{d} p<0.01$ compared with the initial intervention data; ${ }^{e} p<0.05$ and ${ }^{f} p<0.01$ compared with the final control group data. 


\section{Analysis of the parameters in the intervention group}

The pharmaceutical team performed a set of interventions that resulted in the resolution or improvement of the NOMs. A NOM was considered resolved when parameters evaluated reached the standard values. A NOM was considered only ameliorated when parameters did not reach the standard values but were better than they had been at the beginning of the follow-up program. The frequency of resolution or improvement of the NOMs related to necessity found were $82 \%$ for improvement and $49 \%$ for resolution. With NOMs related to efficiency, the results showed improvement in $90 \%$ of cases and resolution in $54 \%$. With NOMs related to safety, the results showed $100 \%$ improvement and $83 \%$ resolution.

The number of medicines in use by the patients from the Intervention group was unchanged during the followup program (3.6 \pm 0.3 vs. $3.7 \pm 0.3$ at the beginning and the end, respectively).

It was observed that $50 \%$ of the patients $(n=17)$ in the Intervention group reported symptoms that were compatible with adverse drug reactions (ADR) to the drugs in use. These patients reported 29 ADRs; of these, gastrointestinal problems $(34.5 \% ; \mathrm{n}=10)$, manifested hypoglycemia $(24.1 \% ; n=7)$, leg pain $(13.9 \% ; n=4)$ and cough $(7.0 \% ; n=2)$ were the most frequent. Headache, weight gain, hyperglycemia, dizziness, cramp and asthenia were reported once $(3.4 \% ; n=1)$.

Adherence to treatment was evaluated in the intervention group using the Morisky test (Morisky, Green, Levine, 1986). Only $20.7 \%(\mathrm{n}=7)$ participants were considered adherent to treatment based on the Morisky scale, and $55.9 \%(\mathrm{n}=19)$ were classified as non-intentional nonadherent subjects; $23.5 \%(\mathrm{n}=8)$ presented both intentional and non-intentional non-adherence tendencies.

\section{Comparison of clinical and laboratory data between the Control and Intervention groups after six months of follow-up}

Table III shows that nearly all clinical parameters evaluated were improved at the end of the study in the Intervention group when compared with their initial values.

The same result was observed when the final data of this group were compared with the final data of the Control group. On the other hand, the final data of the Control group were not different from the data at the beginning of the study. Although there was no significant difference between the SAP and DAP of the Intervention group when compared with their initial data, when these parameters were analyzed only in patients with hypertension, BP values were improved in hypertensive patients in the Intervention group and unchanged in those in the Control group. When the delta of BP of hypertensive patients was calculated, a higher reduction in SAP (Control $=+5 \pm 4 \mathrm{~mm}$ $\mathrm{Hg} v s$. Intervention $=-13 \pm 3 \mathrm{~mm} \mathrm{Hg} ; \mathrm{p}<0.05)$ and DAP (Control $=+1 \pm 4 \mathrm{~mm} \mathrm{Hg} v s$. Intervention $=-8 \pm 3 \mathrm{~mm} \mathrm{Hg}$; $\mathrm{p}<0.05)$ was observed in the patients in the Intervention group.

The observed findings were the same for body weight: although the final values did not differ from the initial ones in both groups, the delta of body weight was higher in the Control than in the Intervention group (Control $=+1 \pm 1 \mathrm{Kg} v s$. Intervention $=-2.6 \pm 1 \mathrm{Kg} ; \mathrm{p}<0.05$ ), which indicates a greater weight reduction in patients who received pharmacist follow-up.

Table IV compares the frequency of improvement or worsening of blood pressure and anthropometric and biochemical measures in the patients in the intervention group with those in the control group.

\section{Assessment of global cardiovascular risk of patients}

Figure 1 shows the degree of cardiovascular risk in Control and Intervention patients before and after the six-month study. Increased coronary heart disease (CHD) risk $(22 \pm 2 \%$ to $26 \pm 3 \mathrm{p}<0.05)$ was observed in the Control group, whereas the intervention group showed a reduction in CHD risk ( $22 \pm 2$ to $14 \pm 2 \% ; \mathrm{p}<0.01)$.

\section{DISCUSSION}

The primary contribution of this study was to demonstrate that patients with MS who were monitored by a public health system had better clinical results, improved health conditions and reduced cardiovascular risks when their care was accompanied by PC service over 6 months, while the same improvements were not observed among the patients who did not receive pharmaceutical intervention.

The effectiveness of pharmacist-physician collaboration is consistent with previous published investigations of the role of pharmacists in the treatment of dyslipidemia, diabetes, hypertension (Ramser et al., 2008; Carter et al., 2009; Kelly, Booth, 2008; McLean et al., 2008) and metabolic syndrome (Hammad et al., 2011). Similarly, our results are also consistent with others studies performed in Brazil on the control of hypertension (Castro et al., 2006), diabetes (Correr et al., 2011) or hypertension and diabetes (Neto et al., 2011). 
TABLE IV - Frequency distribution of changes in anthropometric and biochemical parameters and blood pressure of the Control and Intervention groups

\begin{tabular}{|c|c|c|c|}
\hline & Improved & Worsened & Unchanged \\
\hline \multicolumn{4}{|l|}{ WC } \\
\hline Control & $36.0 \%$ & $64.0 \%$ & - \\
\hline Intervention & $90.9 \%$ & $9 \%$ & - \\
\hline \multicolumn{4}{|l|}{ Weight } \\
\hline Control & $27.3 \%$ & $72.7 \%$ & - \\
\hline Intervention & $85.3 \%$ & $14.7 \%$ & - \\
\hline \multicolumn{4}{|c|}{ Systolic blood pressures } \\
\hline Control & $36.0 \%$ & $32.0 \%$ & $32.0 \%$ \\
\hline Intervention & $56.2 \%$ & $21.9 \%$ & $21.9 \%$ \\
\hline \multicolumn{4}{|c|}{ Diastolic blood pressures } \\
\hline Control & $28.0 \%$ & $40.0 \%$ & $32.0 \%$ \\
\hline Intervention & $53.1 \%$ & $37.5 \%$ & $9.4 \%$ \\
\hline \multicolumn{4}{|l|}{ Glucose } \\
\hline Control & $44.0 \%$ & $56.0 \%$ & - \\
\hline Intervention & $91.2 \%$ & $8.8 \%$ & - \\
\hline \multicolumn{4}{|l|}{ Total Cholesterol } \\
\hline Control & $32.0 \%$ & $60.0 \%$ & $8.0 \%$ \\
\hline Intervention & $79.0 \%$ & $18.0 \%$ & $2.9 \%$ \\
\hline \multicolumn{4}{|l|}{ Triglycerides } \\
\hline Control & $40.0 \%$ & $60.0 \%$ & $0 \%$ \\
\hline Intervention & $67.7 \%$ & $29.4 \%$ & $2.9 \%$ \\
\hline \multicolumn{4}{|l|}{ c-HDL } \\
\hline Control & $33.3 \%$ & $66.7 \%$ & $0 \%$ \\
\hline Intervention & $82.1 \%$ & $14.3 \%$ & $3.6 \%$ \\
\hline \multicolumn{4}{|l|}{ c-LDL } \\
\hline Control & $29.4 \%$ & $70.6 \%$ & $0 \%$ \\
\hline Intervention & $92.8 \%$ & $3.6 \%$ & $3.6 \%$ \\
\hline
\end{tabular}

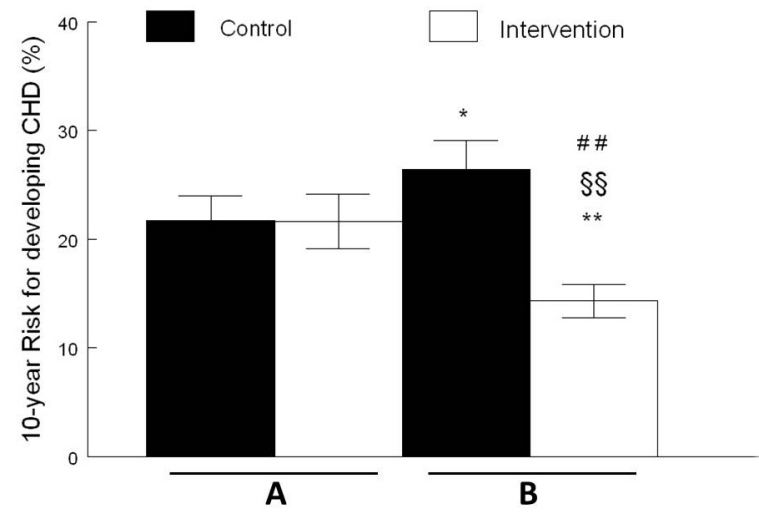

FIGURE 1 - Reduction of cardiovascular risk evaluated through the Framingham score. A: basal values before the interventions; B: values calculated after six month of control or intervention follow-up. Values are expressed as the mean \pm S.E.M. ${ }^{*} p<0.05$ and ${ }^{* *} \mathrm{p}<0.01$ compared with initial Control values; ${ }^{\# \#} \mathrm{p}<0.01$ compared with initial Intervention values; ${ }^{\$} \mathrm{p}<0.01$ compared with final Control values.
When a NOM was found in the patients from the Intervention group, it was analyzed, and the best possible intervention was used to resolve it. The NOMs most frequently identified were related to the effectiveness of the therapy. All patients were taking medication to control diabetes; however, $91.2 \%$ of them had glucose levels greater than $110 \mathrm{mg} / \mathrm{dL}$. Similarly, $73.5 \%$ of patients took medicine to control hypertension, but it was still uncontrolled in $56 \%$ of these patients. These results indirectly indicate a low level of pharmacotherapy adherence, which was confirmed by the Morisky test scores.

Based on the Morisky test, the majority of patients had low behavioral adherence levels, which were most frequently non-intentional. This finding implies that patients, through forgetfulness or neglect, do not use their medicaments correctly. Forgetfulness was reported by Sewitch et al. (2003) as the primary feature responsible for low adherence. 
Therefore, the PC program promoted the correct use of the medicines to improve the effectiveness of the prescribed treatments. There was intervention to clarify how to correctly take the medication and emphasize the importance of correctly following the prescription and remembering to take the medication; in addition, interventions were made in collaboration with the clinical staff to adjust dosage or change medications when necessary. Although changes in adherence levels to treatment were not directly evaluated, changes were indirectly demonstrated by the clinical results.

Another pharmaceutical action was the use of oral and written counseling and educative material to help the patients make and adhere to improved lifestyle changes. The patients were given advice about which foods should be avoided and about exercise; for instance, at least 30 minutes five days a week of light-to-moderate physical activity was recommended for achieving beneficial effects on cardiovascular disease and other chronic diseases such as DM (Clifford et al., 2005), dyslipidemia, and high arterial blood pressure (Sociedade Brasileira de Hipertensão, 2004).

Studies have demonstrated that PC has a positive effect on the control of dyslipidemia (Tsuyuki et al., 2002), glycemia (Adepu, Rasheed, Nagavi, 2007; Clifford et al., 2005; Nau, Pacholski, 2007) and blood pressure (Castro et al., 2006; Clifford et al., 2005; Nau, Pacholski, 2007). Tsuyuki et al. (2002) demonstrated that pharmaceutical interventions improved the process of controlling cholesterol in high-risk patients, and Castro et al. (2006) demonstrated a tendency toward better blood pressure control in resistant hypertensive patients who participated in a PC program (Castro et al., 2006). Lindenmeyer et al. (2006) noted whether the intervention made by pharmacists (in approximately 21 studies) in the care of diabetics had improved adherence to medication treatment, which indicated potential benefits specifically from better educating patients (Lindenmeyer et al., 2006). These results support our findings that $82 \%$ of NOMs related to necessity were at least resolved, which implies the improvement and/or adequacy of the reference values of the majority of patients in their anthropometric parameters and lipid profiles.

The primary difficulty with necessity-related NOMs was that patients did not use their necessary medications. This finding may be explained by the fact that most patients had dislypidemia, but $85.3 \%$ of them did not use medicaments to control it, even though they met the inclusion criteria of the Clinical Protocol and Therapeutic Guideline for the treatment of dislipidemia (Brasil, 2002). Although the latest State Relation of
Essential Medicaments and Exceptional Medicaments (Espírito Santo, 2007) included synvastatin in the group of essential medicaments, during the course of this study, the hypolipemics were considered exceptional and were not widely available in CHCs. Therefore, the Brazilian public health system's limited access to primary healthcare for low-income patients, which prevents them from purchasing these medicaments, explains the frequency of necessity-related NOMs.

NOMs of safety were also frequent, which is usually associated with the onset of an ADR. The fact that most patients in this study were elderly could help explain the high levels of this ADR; elderly patients are more susceptible to adverse reactions during treatment with anti-hypertensive drugs (Benson, Vance-Bryan, Raddatz, 2000). The most frequently reported ADR was gastrointestinal discomfort. A probable explanation for this finding is the fact that most patients use metformin, a medicament capable of causing gastrointestinal events (ADA, 2000). Many patients took their metformin before meals, which promotes gastrointestinal discomfort; these individuals were instructed to take it immediately after meals. With this medicine and others that are known to cause gastrointestinal discomfort, it was recommended that patients take them with plenty of water.

Metabolic syndrome (MS) is a complex disorder consisting of a constellation of risk factors for cardiovascular disease and is responsible for an estimated 2.5 times greater risk of cardiovascular mortality (Sociedade Brasileira de Hipertensão, 2004). Therefore, it is extremely important to delay the progression of MS by controlling the risk factors. Most NOMs were resolved or improved, and this result was sufficient to show better clinical profiles in the patients in the Intervention group compared with those in the Control group. The outcomes of the 10-year CHD risk predictions using Framingham scores showed a clear positive impact of our intervention on reducing the risk of CHD in Intervention group patients.

Additionally, Grymonpre et al. (1994) reinforce the idea that the pharmacist's intervention increases elderly patients' adherence to their therapeutic regimens, and pharmacist's intervention may also promote the reduction of hospital costs by reducing the number of prescriptions, hospitalizations and medications associated with ADR. Thus, as part of the multidisciplinary team providing pharmaceutical care, the pharmacist may improve patients' clinical status through pharmacotherapy follow-up, assisting with effective therapy and the prevention, detection and resolution of NOMs and helping to improve patient quality of life (Strand et al., 2004). 


\section{CONCLUSION}

The present study demonstrates that a PC program used with patients with MS monitored at a primary healthcare center of the Brazilian public health system improves patient health and functioning; there was significant improvement in the Intervention group, and this improvement was greater than that found in the Control group. In the intervention group, identified NOMs were mostly resolved, improved or prevented by pharmaceutical interventions, which resulted in clinical improvements superior to those found in the Control patients, including a decrease in the predicted ten-year risk of developing cardiovascular disease.

\section{ACKNOWLEDGMENTS}

This work was supported with funds from Rede Brasileira de Assistência Farmacêutica e Vigilância de Medicamentos from Instituto Nacional de Ciência e Tecnologia para Inovação Farmacêutica (REBRAFVIME / INCT_if) and Conselho Nacional de Desenvolvimento Cientifico e Tecnológico (CNPq).

\section{REFERENCES}

AGUIAR, P.M.; BALISA-ROCHA, B.J.; BRITO, G.D.; DA SILVA, W.B.; MACHADO, M.; LYRA Jr, D.P. Pharmaceutical care in hypertensive patients: A systematic literature review. Res. Social Adm. Pharm., 2012. Doi:10.1016/j.sapharm.2011.10.001

\section{AMERICAN DIABETES ASSOCIATION. ADA. Medications} for the treatment of diabetes. Alexandria: American Diabetes Association, 2000. p.190. (Clinical Education Series).

ADEPU, R.; RASHEED, A.; NAGAVI, B.G. Effect of patient counseling on quality of life in type-2 Diabetes Mellitus patients in two selected south indian community pharmacies: a study. Indian J. Pharm. Sci., v.69, n.4, p.519524, 2007.

ANDRADE, T.U.; BURINI, D.M.; MELLO, M.O.; BERSÁCULA, N.S.; SALIBA, R.A.D.; BRAVIM, F.T.; BISSOLI, N.S. Evaluation of the satisfaction level of patients attended by a pharmaceutical care program in a private communitarian pharmacy in Vitória (ES, Brazil). Braz. J. Pharm. Sci., v.45, n.2, p.349-355, 2009.
BAENA, M.I.; CALLEJA, M.A.; ROMERO, J.M.; VARGAS, J.; ZARZUELO, A.; JIMÉNEZ-MARTÍN; FAUS, M. Validación de un cuestionario para la identificación de problemas relacionados con los medicamentos en usuarios de un servicio de urgencias hospitalario. Ars Pharm., v.2, n.3-4, p.147-169, 2001.

BENSON, S.; VANCE-BRYAN, K.; RADDATZ, J. Time to patient discontinuation of antihypertensive drugs in different classes. Am. J. Health-Syst. Pharm., v.57, n.1, p.51-54, 2000.

BHATT, S.P.; LUQMAN-ARAFATH, T.K.; GULERIA, R. Nonpharmacological Management of Hypertension. Indian J. Med. Sci., v.61, n.11, p.616-624, 2007.

BRASIL. Ministério da Saúde. Protocolo Clínico e Diretrizes Terapêuticas: dislipidemias em pacientes de alto risco de desenvolver eventos cardiovasculares. Consulta Pública SAS/MS n ${ }^{\circ} 3,2002.134$ p.

CARTER, B.L.; ARDERY, G.; DAWSON, J.D.; JAMES, P.A.; BERGUS, G.R.; DOUCETTE, W.R.; CHRISCHILLES, E.A.; FRANCISCUS, C.L.; XU, Y. Physician and pharmacist collaboration to improve blood pressure control. Arch. Intern. Med., v.169, n.21, p.1996-2002, 2009.

CASTRO, M.S.; FUCHS, F.D.; SANTOS, M.C.; MAXIMILIANO, P.; GUS, M.; MOREIRA, L.B.; FERREIRA, M.B. Pharmaceutical Care Program for patients with uncontrolled hypertension. Am. J. Hypertens., v.19, n.5, p.528-533, 2006.

CORRER, C.J.; MELCHIORS, A.C.; FERNANDEZ-LLIMOS, F.; PONTAROLO, R. Effects of a pharmacotherapy followup in community pharmacies on type 2 diabetes patients in Brazil. Int. J. Clin. Pharm., v.33. n.2, p.273-280, 2011.

CHISHOLM, M.A.; SPIVEY, C.A.; MULLOY, L.L. Effects of a medication assistance program with medication therapy management on the health of renal transplant recipients. Am. J. Health Syst. Pharm., v.64, n.14, p.1506-1512, 2007.

CLIFFORD, R.M.; DAVIS, W.A.; BARRY, K.T.; DAVIS, T.M.E. Effect of a Pharmaceutical Care Program on vascular risk factors in type 2 diabetes. Diabetes Care, v.28, n.4, p.771-776, 2005. 
COMITÉ DE CONSENSO. Tercer Consenso de Granada sobre Problemas Relacionados con Medicamentos (PRM) y Resultados Negativos asociados a la Medicación (RNM). Ars. Pharm., v.48, n.1, p.5-17, 2007.

ESPÍRITO SANTO (ES). (Estado). Secretaria de Estado da Saúde. Gerência de Assistência Farmacêutica. Relação Estadual de Medicamentos Essenciais e Medicamentos Excepcionais - REMEME. Vitória, 2007. 342 p.

FORNOS, J.A.; ANDRÉS, N.F.; ANDRÉS, J.C.; GUERRA, M.M.; EGEA, B. Pharmacotherapy follow-up program in patients with type-2 diabetes in community pharmacies in Spain. Pharm. World Sci., v.28, n.2, p.65-72, 2006.

GRUNDY, S.M.; CLEEMAN, J.I.; DANIELS, S.R.; DONATO, K.A.; ECKEL, R.H.; FRANKLIN, B.A.; GORDON, D.J.; KRAUSS, R.M.; SAVAGE, P.J.; SMITH, S.C.; SPERTUS, J.A.; COSTA, F. Diagnosis and management of the metabolic syndrome: an American Heart Association/ National Heart, Lung, and Blood Institute Scientific Statement. Circulation, v.112, n.17, p.2735-2752, 2005.

GRYMONPRE, R.E.; WILLIAMSON, D.A.; HUYNH, D.H.; DESILETS, L.M. Community-based pharmaceutical care model for the elderly: Report on a pilot project. Int. J. Pharm. Pract., v.2, n.4, p.229-234, 1994.

HAMMAD, E.A.; YASEIN, N.; TAHAINEH, L.; ALBSOULYOUNES, A.M. A randomized controlled trial to assess pharmacist- physician collaborative practice in the management of metabolic syndrome in a university medical clinic in Jordan. J. Manage Care Pharm., v.17, n.4, p.295$303,2011$.

HILL, M.N.; MILLER, N.H.; DEGEEST, S. American Society of Hypertension Writing Group, Materson BJ, Black HR, Izzo JL Jr, Oparil S, Weber MA. Adherence and persistence with taking medication to control high blood pressure. $J$. Am. Soc. Hypertens., v.5, n.1, p.56-63, 2011.

HORSWELL, R.L.; WASCOM, C.K.; CERISE, F.P.; BESSE, J.A.; JOHNSON, J.K. Diabetes mellitus medication assistance program: relationship of effectiveness to adherence. J. Health Care Poor U., v.19, n.3, p.677-686, 2008.

KELLY, C.J.G.; BOOTH, G. Pharmacist-led structured care for patients with diabetic nephropathy. Brit. J. Diabetes. Vasc. Dis., v.8, n.2, p.86-88, 2008.
LAKKA, H.M.; LAAKSONEN, D.E.; LAKKA, T.A.; NISKANEN, L.K.; KUMPUSALO, E.; TUOMILEHTO, J.; SALONEN, J.T. The metabolic syndrome and total and cardiovascular disease mortality in middle-aged men. JAMA., v.288, n.21, p.2709-2716, 2002.

LESSA, I. Doenças crônicas não transmissíveis. In:__ O adulto brasileiro e as doenças da modernidade: Epidemiologia das doenças não transmissíveis. São Paulo: Hucitec; Rio de Janeiro: Abrasco, 1998. 284 p.

LINDENMEYER, A.; HEARNSHAW, H.; VERMEIRE, E.; VAN ROYEN, P.; WENS, J.; BIOT, Y. Interventions to improve adherence to medication in people with type 2 diabetes mellitus: a review of the literature on the role of pharmacists. J. Clin. Pharm. Ther., v.31, n.5, p.409-419, 2006.

MACHUCA M, FERNÁNDEZ-LLIMÓS F, FAUS MJ. Método Dáder: guía de seguimiento fármacoterapéutico. Granada: UGR, 2003. 128 p.

MCLEAN, D.L.; MCALISTER, F.A.; JOHNSON, J.A.; KING, K.M.; MAKOWSKY, M.J.; JONES, C.A.; TSUYUKI, R.T. A randomized trial of the effect of community pharmacist and nurse care on improving blood pressuremanagement in patients with diabetes mellitus: study of cardiovascular risk intervention by pharmacists-hypertension (SCRIP-HTN). Arch. Intern. Med., v.168, n.21, p.2355-2361, 2008.

MORISKY, D.E.; GREEN, L.W.; LEVINE, D.M. Concurrent and predective validity of self-reported measure of medication adherence. Med. Care, v.24, n.1, p.67-74, 1986.

NATIONAL HIGH BLOOD PRESSURE EDUCATION PROGRAM. The Seventh Report of the Joint National Committee on Prevention, Detection, Evaluation, and Treatment of High Blood Pressure. Bethesda (MD): National Heart, Lung, and Blood Institute (US), 2004.86 p.

NAU, D.P.; PACHOLSKI, A.M. Impact of Pharmacy care services on patients perceptions of health care quality for diabetes. J. Am. Pharm. Assoc., v.47, n.3, p.358-365, 2007.

NCEP - Third Report of the National Cholesterol Education Program. Expert panel of detection, evaluation, and treatment of high blood cholesterol in adults (adult treatment panel III). Final report. Circulation, v.106, n.25, p.3143-421, 2002. 
NETO, P.R.; MARUSIC, S.; DE LYRA JÚNIOR, D.P.; PILGER, D.; CRUCIOL-SOUZA, J.M.; GAETI, W.P.; CUMAN, R.K. Effect of a 36-month pharmaceutical care program on the coronary heart disease risk in elderly diabetic and hypertensive patients. J. Pharm. Pharm. Sci., v.14, n.2, p.249-263, 2011.

NI. Y.; CHEN, Y.; HUANG, W. The effect of pharmaceutical care programs on blood pressure control in individuals with hypertension: a meta-analysis. J. Pharm. Technol., v.25, n.5, p.292-296, 2009.

PAN-AMERICAN HEALTH ORGANIZATION (PAHO). Brazilian Consensus for Pharmaceutical Care. Available at: <www.opas.org.br/medicamentos>. Accessed on: 20 oct. 2007.

RAMSER, K.L.; SPRABERY, L.R.; GEORGE, C.M.; HAMANN, G.L.; VALLEJO, V.A.; DORKO, C.S.; KUHL, D.A. Physician-pharmacist collaboration in the management of patients with diabetes resistant to usual care. Diabetes Spect., v.21, n.3, p.209-214, 2008.

ROBINSON, J.D.; SEGAL, R.; LOPEZ, L.M.; DOTY, R.E. Impact of a pharmaceutical care intervention on blood pressure control in a chain pharmacy practice. Ann. Pharmacother., v.44, n.1, p.88-96, 2010.

ROUGHEAD, E.E.; SEMPLE, S.J.; VITRY, A.I. Pharmaceutical care services: a systematic review of published studies, 1990 to 2003, examining effectiveness in improving patient outcomes. Int. J. Pharm. Pract., v.13, n.1, p.53-70, 2005.
SEWITCH, M.J.; ABRAHAMOWICZ, M.; BARKUN, A.; BITTON, A.; WILD, G.E.; COHEN, A;. DOBKIN, P.L. Patient nonadherence to medication in inflammatory Bowel disease. Am. J. Gastroenterol., v.98, n.7, p.1535-1544, 2003.

SOCIEDADE BRASILEIRA DE HIPERTENSÃO. I Diretriz Brasileira de Diagnóstico e Tratamento da Síndrome Metabólica. Rev. Bras. Hipert., v.7, n.4, p.1-27, 2004.

STRAND, L.M.; LINDA, M.; CIPOLLE, R.J.; MORLEY, P.C. The impact of pharmaceutical care practice on the practitioner and the patient in the ambulatory practice setting: twenty- five years of experience. Curr. Pharm. Design, v.10, n,31, p.3987-4001, 2004.

TSUYUKI, R.T.; JOHNSON, J.A.; TEO, K.K.; SIMPSON, S.H.; ACKMAN, M.L.; BIGGS, R.S.; CAVE, A.; CHANG, W.C.; DZAVIK, V.; FARRIS, K.B.; GALVIN, D.; SEMCHUK, W.; TAYLOR, J.G. A Randomized trial of the effect of community pharmacist intervention on cholesterol risk management: the Study of Cardiovascular Risk Intervention by Pharmacists (SCRIP). Arch. Intern. Med., v.162, n.10, p.1149-1155, 2002.

WILSON, P.W.F.; D’AGOSTINO, R.B.; LEVY, D.; BELANGER, A.M.; SILBERSHATZ, H.; KANNEL, W.B. Prediction of coronary heart disease using risk factor categories. Circulation, v.97, n,18, p.1837-1847, 1998.

Received for publication on $21^{\text {st }}$ March 2012 Accepted for publication on $06^{\text {th }}$ July 2012 